\title{
Cognitive Impairment in Primary and Secondary Headache Disorders
}

\author{
Olivia Begasse de Dhaem ${ }^{1} \cdot$ Matthew S. Robbins ${ }^{2}$
}

Accepted: 20 February 2022 / Published online: 3 March 2022

(c) The Author(s), under exclusive licence to Springer Science+Business Media, LLC, part of Springer Nature 2022

\begin{abstract}
Purpose of Review To critically evaluate the recent literature on cognitive impairment and headache.

Recent Findings Neurocognitive symptoms are prevalent, debilitating, and occur often with both primary and secondary headache disorders.

Summary This is a "narrative review of the current literature in PubMed on cognitive function and headache." Migraine is associated with cognitive impairment years before a migraine diagnosis. In young and middle-aged adults, migraine is associated with deficits in attention, executive function, processing speed, and memory. It is unlikely that migraine is associated with dementia. Although methodologically difficult to assess, there does not seem to be an association between tension-type headache and cognitive dysfunction. In early to midlife, cluster headache seems to be associated with executive dysfunction. Several secondary headache syndromes relevant to clinicians managing headache disorders are associated with poorer cognitive performance or distinctive cognitive patterns, including those attributed to chronic cerebral or systemic vascular disorders, trauma, and derangements of intracranial pressure and volume, including frontotemporal brain sagging syndrome.
\end{abstract}

Keywords Migraine $\cdot$ Cognition $\cdot$ Dementia $\cdot$ Cognitive function

\begin{tabular}{|c|c|}
\hline \multicolumn{2}{|c|}{ Abbreviations } \\
\hline ICHD & $\begin{array}{l}\text { International Classification of Headache } \\
\text { Disorders }\end{array}$ \\
\hline NHIRD & National Health Insurance Research Database \\
\hline NHIS & National Health Insurance Service \\
\hline $\mathrm{MoCA}$ & Montreal Cognitive Assessment \\
\hline CADASIL & $\begin{array}{l}\text { Cerebral autosomal dominant arte- } \\
\text { riopathy with subcortical infarcts and } \\
\text { leukoencephalopathy }\end{array}$ \\
\hline CARASIL & $\begin{array}{l}\text { Cerebral autosomal recessive arte- } \\
\text { riopathy with subcortical infarcts and } \\
\text { leukoencephalopathy }\end{array}$ \\
\hline MELAS & $\begin{array}{l}\text { Mitochondrial encephalopathy, lactic acido- } \\
\text { sis, and stroke-like episodes }\end{array}$ \\
\hline CAA & Cerebral amyloid angiopathy \\
\hline
\end{tabular}

This article is part of the Topical Collection on Secondary Headache

Olivia Begasse de Dhaem

begassededhaem@gmail.com

1 Department of Neurology, Stamford Hospital, Stamford, CT, USA

2 Department of Neurology, Weill Cornell Medical College, New York Presbyterian Hospital, New York, NY, USA

\begin{tabular}{|c|c|}
\hline CAA-ri & $\begin{array}{l}\text { Cerebral amyloid angiopathy-related } \\
\text { inflammation }\end{array}$ \\
\hline RVCLSM & $\begin{array}{l}\text { Retinal vasculopathy with cerebral leukoen- } \\
\text { cephalopathy and systemic manifestations }\end{array}$ \\
\hline MMA & Moyamoya angiopathy \\
\hline SMART & $\begin{array}{l}\text { Stroke-like migraine attacks after radiation } \\
\text { therapy }\end{array}$ \\
\hline PRES & $\begin{array}{l}\text { Posterior reversible encephalopathy } \\
\text { syndrome }\end{array}$ \\
\hline RCVS & $\begin{array}{l}\text { Reversible cerebral vasoconstrictive } \\
\text { syndrome }\end{array}$ \\
\hline ImPACT & $\begin{array}{l}\text { Immediate post-concussion assessment and } \\
\text { cognitive test }\end{array}$ \\
\hline FBSS & Frontotemporal brain sagging syndrome \\
\hline
\end{tabular}

\section{Background}

Given the ever-growing crisis of dementia in our aging population, it is crucial to study the conditions associated with cognitive decline and evaluate ways to reduce this growing burden [1]. Headache disorders are also exceedingly common, with a lifetime prevalence of more than $90 \%$ [2]. Headache specialists need to be able to answer questions from patients and colleagues on the association between headache diagnoses and the risk of cognitive impairment. 
Some conditions associated with cognitive dysfunction might initially present with headaches. Hence, this review focuses on interictal cognitive assessment for both primary and secondary headache disorders in adults. Early diagnosis is important as progression to cognitive impairment can sometimes be prevented or reduced. This narrative review serves as both an update to the 2018 review on migraine and cognitive function [3] and a unique review of cognitive function in other headache disorders, including secondary headache syndromes relevant to clinical practice for the headache specialist that is prominently associated with cognitive impairment. It complements an excellent 2019 review on migraine and cognitive function that discussed cognitive function during attacks and mechanistic hypotheses of interictal cognitive dysfunction (which may include functional thalamocortical disconnection; low serotonin levels between attacks correlating to decreased habituation; functional connectivity differences on fMRI studies in the hippocampus, parahippocampal gyrus, and orbitofrontal cortex which may affect cognitive processing; overload of the brain areas responsible for both cognition and pain processing) [4•].

\section{Methods}

PubMed was initially searched for "headache cognitive" (3441 results) and "headache dementia" (845 results). Then, PubMed was searched sequentially for common headache disorders listed in the third edition of the International Classification of Headache Disorders (ICHD-3) and their association with cognitive impairment, cognitive function, or dementia in April 2019. For example, "migraine," "cognitive," "cognition," and "dementia" were searched, leading to 1768 articles. Then, "tension-type headache," "tension headache," "cognitive," "cognition," and "dementia" were searched leading to 239 articles. Then, "cluster headache," "cognitive," "cognition," and "dementia" were searched, leading to 113 articles. The search was sequentially performed for the different ICHD-3 headache disorders. ICHD-3 headache disorders not seemingly associated with impaired cognition were not included. Sickle cell disease (SCD), stroke-like migraine attacks after radiation therapy (SMART) syndrome, and frontotemporal brain sagging syndrome were added to the list searched due to authors' experience with questions from colleagues on these topics.

Articles were screened for relevance by the first author based on title and abstract first. The first author read the full text of selected studies to ensure they assessed cognitive function in people with headache disorders. Articles assessing cognitive function during a primary headache attack were excluded. The headache disorder diagnoses were made by positive validated epidemiologic surveys, self-reports, national database diagnostic code, or clinical evaluation diagnoses based on the ICHD-3 criteria. Although there was no restriction on language, only full-text studies in English ended up being selected for further review. Studies were searched from inception to October 2021. The bibliographic information was recorded with Zotero. The second author checked the thoroughness of the initial search.

\section{Migraine and Cognition}

The available evidence up to 2018 suggested (1) an association between worse performance in verbal comprehension, attention, and school grades in children before the onset of migraine attacks compared to peers who did not develop migraine later, which suggests that cognitive dysfunction may be associated with a predisposition to later develop migraine and not the consequence of migraine attacks [5] and (2) an association between migraine and worse performance in terms of attention, calculation, orientation, executive function, language, psychomotor speed, visuo-constructive skills, and memory in the first 50 years of life [6-15], and no strong evidence for an association between migraine and age-related cognitive decline.

There is evidence to support an association between migraine and cognitive dysfunction interictally up to around midlife, although there are also small conflicting case-control studies. A recent meta-analysis of 17 articles published up to January 2020 showed an association between and worse performance in complex attention (12 studies), immediate memory (5 studies), and spatial cognition (6 studies). The heterogeneity in study design, sample, cognitive assessments used, and type of data reported (raw vs age-adjusted) limits meta-analyses on the topic [16•]. In a cross-sectional analysis of 4208 non-clinic-based participants with a mean age of 50 years old, migraine was associated with worse performance in executive function, attention, processing speed, immediate recall, and linguistic skills [17]. From a cross-sectional analysis of 478 primary care patients with a mean age of 66.4 years (range 50-95), there was no association between migraine and performance in executive function, language skills, working memory, verbal or visual episodic memory, and inhibitory control, but migraine was associated with slower performance in attention and processing speed, which suggests that the early association between migraine and attention deficits may persist past midlife [18]. There were 13 case-control studies of young adults (mean ages of those studies ranging from 24.5 to 46) showing an association between migraine and lower performance in memory, attention, psychomotor speed, executive function [6-15, 19-21]. Depression and anxiety did not play a role in this association [8-10, $12,13,19,20]$. Acute and preventive medication use did not affect the results either [11]. Interestingly, subjective 
cognitive complaints were found to correlate with depression and anxiety but not with objective cognitive measures [19]. However, four case-control studies of mean age 29 to 40.5 years old suggested otherwise and showed no difference or better performance from the group with migraine [22-25].

Migraine is associated with radiographic brain lesions on MRI, including deep white matter intensities, but there is no evidence that this association impacts cognitive function [26, 27]. The mean participant age of 42 years old of the two national database retrospective studies from Taiwan based on medical claim codes seems too young to be able to carefully assess for a potential association between migraine and dementia claim code [28, 29]. More recently, a retrospective case-control study of the Korean National Health Insurance Service of patients at least 60 years old identified 11,438 patients with medical claim code of Alzheimer's dementia and matched them with controls without medical claims for dementia. $7.7 \%$ of patients with Alzheimer's disease medical claim had prior migraine claims vs $6.3 \%$ of controls $(p<0.01)$ with an adjusted odds ratio of 1.13 (95\% CI 1.05-1.23) for migraine in the dementia group [30]. Although statistically significant, this difference was small and may not account for factors such as selection bias.

Two recent studies suggest an association between migraine and dementia in women only. A Canadian population-based prospective study of 679 participants of at least 65 years of age with a mean age of 76 years and negative screen for dementia using a Modified Mini-Mental State Examination at enrollment showed $7.5 \%$ of participants at 5-year follow-up were clinically diagnosed with dementia. There was an association between a history of migraine and Alzheimer's dementia in women: $23.5 \%$ of participants diagnosed with Alzheimer's dementia had migraine (all women) vs $9.9 \%$ of cognitively intact participants $(p=0.01)$. The odds ratio for a history of migraine in participants diagnosed with any type of dementia was 2.23 (95\% CI 1.06-4.66). Depression and cardiovascular diseases did not play a role in the association. There was no association between migraine and vascular dementia [31]. A retrospective cohort study of 7454 patients from UK general practices with mean age 67.7 years old (range 60-80 years old) showed an association between migraine and all-cause dementia (hazard ratio of 1.65, 95\% CI 1.19-2.11) and Alzheimer's disease (hazard ratio of 2.27, 95\% CI 1.42-3.12) in women [32]. Cardiovascular diagnoses, depression, brain injury, alcohol abuse, epilepsy, and Parkinson's disease were accounted for in the regression analyses [32]. Migraine and dementia diagnoses were assessed using ICD 10 codes with the limitation that migraine diagnosis is often made in younger patient populations [32]. These two studies raise the question of why such association would only be found in women and whether confounders or biases may account for those findings. Their results conflict with the other studies discussed, including the large prospective cohort Women's Health Study of women aged at least 65 -year-old where there was no difference in scores for verbal memory, language and executive function, and general cognitive function between the participants with migraine (853 participants, $13.4 \%$ ) and the participants without migraine (5496 participants) [33].

Seven large prospective studies support that migraine is not associated with dementia. In a prospective cohort study of 6708 participants with a mean age of 64.6 years old, the 1021 participants with migraine performed the same or better in terms of mini-mental state evaluation, immediate recall and delayed recall, processing speed, reading, naming, interference, executive function, language skills, and dexterity [34]. In a prospective community cohort study with mean participant age of 50-year-old, the migraine group (204 participants) had significantly less decline in memory testing over time than the non-migraine group (1244 participants) [35]. When using the most recent data from the Nord-Trøndelag Health Surveys, migraine was inversely associated with dementia [36]. The odds ratio for migraine in participants with dementia adjusted for gender, age, education, smoking, anxiety, depression, and severe comorbid conditions was $0.44 ; 95 \%$ CI $0.22-0.77$ [36]. This later study used the same HUNT2 headache questionnaires and dementia registry as the prior study, but a larger sample of participants with confirmed dementia was identified (746) [36, 37]. Of note, the mean age for dementia diagnosis was 79.9 years old [37]. Similarly, the longitudinal Maastricht Aging Study of 1869 participants suggested that migraine was not associated with cognitive aging [38]. Medication use did not affect the results either [39]. A 21-year prospective cohort study of 12,495 participants of ages 51-70 showed no association between migraine and dementia [40]. In this study, dementia was assessed with cognitive and neuropsychological evaluations followed by clinical assessment [40]. In a 5 -year longitudinal prospective study of 275 people from the community (216 without headaches, 35 with migraine headaches, 24 with non-migraine headaches) of mean age 70.4 , the prevalence of cognitive decline was $11.4 \%$, with similar proportions amongst all groups. Once again, people with migraine had more subjective cognitive complaints and screened higher on the depression scale than controls, but these did not impact their cognitive results. Interestingly, people with migraine had lower baseline scores in terms of attention and processing speed, which is consistent with the interictal cognitive deficits observed earlier in life described in the studies above. Adjusting for the baseline difference did not change the results [41]. A cross-sectional and longitudinal study of 3069 participants of mean age 73.6 from the Swedish National Study on Aging and Care in Kungsholmen (SNAC-K) supported the lack of association between migraine and dementia [42•]. Use of specific and 
nonspecific migraine medications, age, sex, cerebrovascular disease, and APOE4 allele did not impact the results [42•]. Two cross-sectional observational studies of the mean age in the $60 \mathrm{~s}$ did not find an association between migraine and cognitive performance [43-45].

\section{Familial Hemiplegic Migraine}

A small study of cognitive function in six patients with genetically proven (missense mutation T666M on chromosome 19) familial hemiplegic migraine showed deficits in attention, executive function, visuo-constructive skills, and dexterity [46]. All six patients had cerebellar ataxia and atrophy, but none were found to have depression or anxiety [46]. The patients demonstrated normal verbal intelligence and memory mental arithmetic. Seven years later, those six patients did not show cognitive decline except for some worsening in visuo-constructive skills [47]. A case report of a boy with an ATP1A2 mutation who goes to school and has good social skills showed he had lower performance in computational skills and three-dimensional spatial awareness compared to his peers [48]. An observational study of prospective and standardized neuropsychological assessment of 18 children with CACNA1A mutations (14 with hemiplegic migraine) showed a wide variety in the severity and domains of cognitive dysfunctions and could not identify a specific cognitive profile [49]. Vermian atrophy was associated with a higher risk of cognitive impairment [49]. It may be important to regularly evaluate and monitor people with hemiplegic migraine for potential cognitive dysfunction.

\section{Tension-Type Headache and Cognition}

There is little data regarding the potential association between tension-type headaches and cognitive impairment. Given the high lifetime prevalence of tension-type headaches, uncovering a specific risk would be methodologically challenging and presumably very nonspecific [50]. Unlike migraine, patients diagnosed with tension-type headaches in early adulthood had neither cognitive deficits nor poorer school performance in childhood [51]. Retrospective studies extracted from medical claims in Taiwan found that patients with tension-type headache are at a slightly higher risk of dementia with an odds ratio of 1.77 (95\% CI: 1.411-2.224; $P<0.001$ ), but the mean participant age was 49 years, which is too low to evaluate for dementia $[29,52]$. In a crosssectional study of neurology clinic patients of mean age 35.8 years old, patients with chronic tension-type headache screened higher for depression, anxiety, and insomnia and performed worse in visual-spatial skills, executive function, and attention testing compared to patients without chronic tension-type headache [53]. However, it was not assessed whether depression, anxiety, and insomnia could be confounders of the association found between chronic tensiontype headache and worse cognitive performance [53].

\section{Cluster Headache and Cognition}

There is not much data on the potential association between cluster headache and cognition. However, three small crosssectional studies suggest an association between cluster headache and executive dysfunction. One looking at 27 patients with chronic cluster headache, 26 with episodic cluster headache in the active period, 22 with episodic cluster headache outside the active period, and 31 healthy controls matched for age (although participant age is unclear) found a pattern of lowest executive function scores for patients with chronic cluster headache with gradually better scores with episodic cluster headache in the active period and episodic cluster headache outside the active period in between and controls with the best cognitive scores on the other end of the spectrum [54]. Another study of 40 patients with episodic cluster headache and 40 healthy controls with a mean age of 48.9 years showed that episodic cluster headache was associated with poorer performance in attention, executive function, language, and working memory outside of the cluster attack period even when adjusting for duration of disease, anxiety, depression, or sleep [55]. A third study of 21 participants with episodic cluster headache of mean age 47 years did not find a difference in terms of executive function, selective attention, working memory, and verbal fluency between periods inside and outside of the active cluster, but the participant scored significantly lower than normative data, especially in cognitive flexibility and processing speed [56]. To our knowledge, there is no available evidence on cluster headache and dementia.

\section{Headaches Attributed to Genetic Vasculopathies}

\section{Headache Attributed to Cerebral Autosomal Dominant Arteriopathy with Subcortical Infarcts and Leukoencephalopathy (CADASIL)}

Up to $40 \%$ of patients with CADASIL initially present with headaches similar to migraine with aura, even more so during and around the time of pregnancy [57-60]. One-third of cases present with migraine-with-aura-like headaches when patients are in their thirties and progress to recurrent small deep strokes and subcortical dementia about 15 years later [61]. The cognitive dysfunction related to CADASIL seems to stem from white matter microstructural damage [62-64]. A cross-sectional study of 32 patients of mean age 53 years 
old with CADASIL showed that age, headache intensity, and female gender were associated with a higher burden of white matter hyperintensities [65]. About $28-77 \%$ of patients with CADASIL are affected by cognitive decline, mostly in executive function, attention, psychomotor speed, visuoconstructive skills $[57,58,66]$. CADASIL dementia is also associated with gait disturbance, urinary incontinence, and pseudobulbar palsy [58]. Unfortunately, there is no definitive treatment for CADASIL. Stroke risk factors have to be addressed, and patients are managed symptomatically. Donepezil did not meet the primary endpoint in a randomized control trial for subcortical vascular cognitive impairment in CADASIL [67].

\section{Headache Attributed to Mitochondrial Encephalopathy, Lactic Acidosis, and Stroke-like Episodes (MELAS)}

There are two possible types of headaches associated with MELAS: “(1) recurrent migraine attacks (with or without aura) or (2) acute headache preceding or associated with focal neurological deficits and/or seizures" [61]. About half of patients with the 3243A $>\mathrm{G}$ mutation develop cognitive deficits in executive function, attention, and visuo-constructive skills $[68,69]$. In a prospective study of 33 patients with the $3243 \mathrm{~A}>\mathrm{G}$ mutation of mean age 41 years old, there was no clear progression in cognitive decline over three years [68]. Currently, the management of MELAS remains symptomatic [70]. If present, sensorineural deafness has to be addressed. A case report of a young woman suggests that computerized cognitive training with motor training can help with the MELAS cognitive impairment [71].

\section{Migraine-like Aura Attributed to Cerebral Amyloid Angiopathy (CAA)}

Over $40 \%$ of patients with CAA without inflammation have cognitive decline [72]. The CAA-migraine-aura-like transient focal neurological episodes (TFNE) are hypothesized to originate from cortical spreading depression emanating from the cortex adjacent to the small hemorrhages $[61,73]$.

The cerebral amyloid angiopathy-related inflammation (CAA-ri) subtype is defined by rapidly progressive cognitive decline or behavioral changes (48-76\% of patients), headaches (38.7-41\%), seizures (31-36.7\%), T2-weighted hyperintense MRI lesions (Fig. 1), and histological evidence of CAA-associated vascular inflammation [74-77]. CAA-ri tends to initially present with an acute headache and acute or subacute cognitive decline in orientation, attention, episodic memory, personality, and behavioral changes $[75-78,79 \bullet]$. Figure 1 presents an illustrative case. CAA-ri is important to be recognized as $57.6 \%$ of patients clinically improve with immunosuppressive treatment (mostly prednisone, but also cyclophosphamide, azathioprine, and mycophenolate mofetil), and treatment can also help prevent recurrence [80, 81 ]. However, $14.1 \%$ did not improve, and $28.2 \%$ had a further decline in neurological function [80].

\section{Headache Attributed to Syndrome of Retinal Vasculopathy with Cerebral Leukoencephalopathy and Systemic Manifestations (RVCLSM)}

The neurological manifestations of this systemic disease include migraine-like headaches mostly without aura (59\% of patients), cognitive impairment $(56 \%)$, seizures (17\%), and focal neurological deficits (68\%) [82]. Since the migraine-like attacks occur two decades before the characteristic systemic manifestations of the disorder, it is important for headache specialists to be aware of this disease [82]. The major features of cognitive deficits are: "bradyphrenia, apathy, irritability, and impaired memory and judgment" [82]. There is no known treatment to date; management is symptomatic [82, 83].

\section{Headache Attributed to Moyamoya Angiopathy (MMA)}

The pathophysiology of the association between MMA and headache in both adults and children is not fully understood $[61,84]$ MMA-associated headaches can resemble migraine with aura, hemiplegic migraine, tension-type headache, and cluster headaches $[61,85]$. Since headache can be the initial symptom of MMA and there is no specific headache phenotype associated with MMA, neurovascular imaging should be considered early in patients with new-onset refractory headaches [84].

Childhood-onset MMA is associated with progressive intellectual disability in 21 to $50 \%$ of cases $[86,87]$. In a meta-analysis including six studies on 153 adults with MMA of median age 40.1 years, the median percentage with cognitive impairment was $31 \%$ (range, 0 to $69 \%$ ), and the median IQ was 95 (range 94-99) [88]. More specifically, the median proportion of patients with deficits in memory was $37 \%$, processing speed $28 \%$, attention and executive functions $37 \%$, visuospatial skills $23 \%$, and language 35\% [88]. Although cognitive impairment in adults with MMA has long been assumed to be secondary to strokes, there is evidence for cognitive deficits (mostly in short-term memory and computation) in patients with asymptomatic MMA raising the hypothesis that cognitive deficits stem from chronic hypoperfusion [88, 89]. In a case-control study of 26 patients with asymptomatic MMA and 20 controls of mean age 46 years, the MMA group had lower performance in terms of computational ability and short-term memory [90]. In a case-control study of 21 participants with asymptomatic MMA, 19 
Fig. 1 Illustrative case of cerebral amyloid angiopathyrelated inflammation. An 80-year-old woman with a history of hypertension, hyperlipidemia, and multiple transient ischemic attacks presented with 1 day of acute onset, progressive right hemicranial headache, nausea, and vomiting. Examination revealed an elderly woman with normal vital signs, severe inattention, left homonymous hemianopsia, and left hemispatial neglect. Brain MRI revealed small scattered hypointensities on axial gradient echo sequences (A) as well as prominent regions of confluent hyperintensity on axial FLAIR sequences in the right temporal and bilateral occipital white matter $(\mathbf{B})$. She was treated with intravenous corticosteroids with clinical resolution over a few days and radiographic improvement on axial FLAIR sequences after 3 months (C)
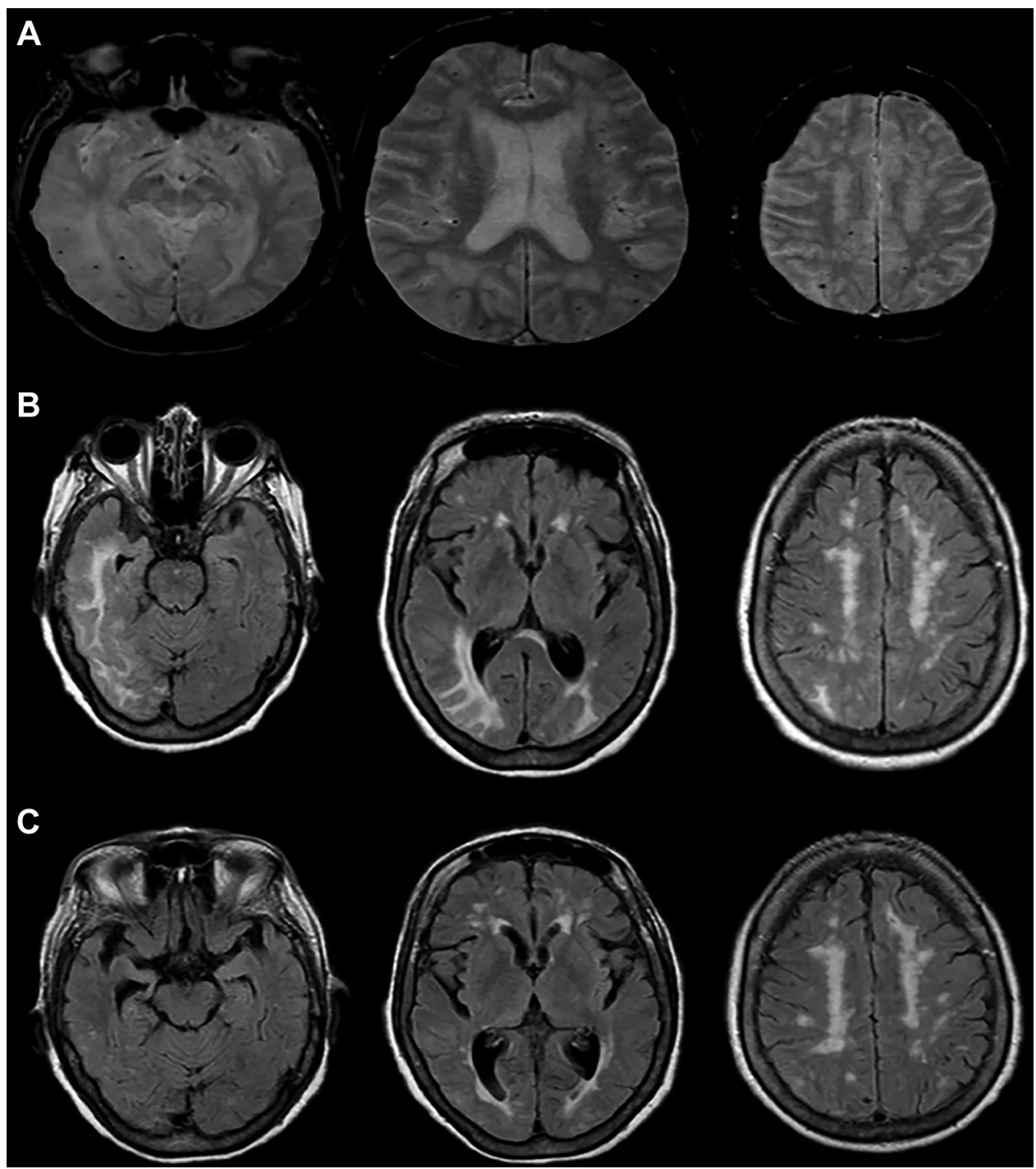

participants with MMA-related strokes, and 20 controls of mean age around 41 years, both groups MMA had worse performance than the control group in spatial imagination, working memory, computational ability, and short-term memory and the group with MMA-related strokes performed worse than the group with asymptomatic MMA in complex arithmetic and short-term memory [91]. Unfortunately, there is no known treatment to date to prevent MMA-related cognitive dysfunction. In an observational study of 53 patients with MMA of mean age 51 years, 7 initially presented with headache (13\%), and 30 underwent revascularization (57\%) [89]. About 11 years after initial diagnosis, deficits in attention, memory, conceptualization, mental flexibility, and inhibitory control were observed regardless of whether the patients underwent revascularization (28 underwent superficial temporal artery-middle cerebral artery anastomosis, and 2 patients underwent encephaloduroarteriosynangiosis) [89].

\section{Headaches Attributed to Arteritis}

Headache is the dominant symptom of arteritides and sometimes the only symptom [61].

\section{Giant Cell Arteritis}

Some patients do not present with the typical features of giant cell arteritis, so this diagnosis should be considered in anyone at least 50 years old with new-onset or different headaches $[92,93]$. Even if $72 \%$ of patients with giant cell arteritis eventually have headaches, headache is the initial symptom in only $32 \%$ of patients $[92,94]$. The typical headache is usually of acute or subacute onset in temporal location ( $50 \%$ of the time), associated with scalp tenderness. It can be persistent or intermittent, mild or severe, and can mimic primary headaches such as migraine or cluster headache [92]. 
Even if giant cell arteritis dementia is rare, it is important to be identified because it might stabilize or modestly improve with a high dose and prolonged course of corticosteroids [95-97]. Dementia associated with giant cell arteritis is thought to be a form of multi-infarct dementia, especially when there is a high infarct burden in the vertebrobasilar system [95, 97]. A hypothesis is that the cognitive changes are thought to be due to thalamic and inferomesial temporal lobe infarcts [95, 97]. Patients can have abrupt confusion during active giant cell arteritis episodes and might progress to a more chronic dementia [95-99].

\section{Primary and Secondary Angiitides of the Central Nervous System}

A detailed assessment of other various CNS angiitis is beyond the scope of this review. These diagnoses should be considered in patients with "subacute or chronic headache with cognitive impairment or chronic aseptic meningitis" [100].

\section{Stroke-like Migraine Attacks after Radiation Therapy (SMART) Syndrome}

Episodes of SMART syndrome occur acutely after about one to 37 after radiation, present with headache (35\% of patients), focal neurological deficits $(77 \%)$, cognitive changes (50\%), and seizures (35\%), and are associated with cortical-subcortical FLAIR hyperintensities and cortical enhancement on MRI [101, 102]. The cognitive impairments include confusion, psychomotor slowing, and aphasia [102]. SMART syndrome might initially present with headaches resembling migraine. This syndrome is important to be recognized as it is partly reversible either spontaneously or with steroids in $50-85 \%$ of patients [102-104].

\section{Posterior Reversible Encephalopathy Syndrome (PRES) and Reversible Cerebral Vasoconstrictive Syndrome (RCVS)}

Both syndromes can initially present with severe headaches, including a thunderclap phenotype [105]. There is a paucity of evidence in the literature on the long-term cognitive outcomes of PRES and RCVS, as the risk of such outcomes may depend more specifically on the underlying associated disorder or inciting factor. Since both PRES and RCVS are considered "reversible," patients with longstanding cognitive impairment might also be given another diagnosis.

Case reports describe three women of 30,51 , and 59 years old with persistent memory, attention, visuospatial, and executive deficits up to 11 months after their PRES diagnoses with persistent MRI abnormalities [106, 107]. Another case report of a 76-year-old patient with atypical PRES suggested that her "PRES" episode precipitated the onset of her dementia syndrome, but she might have had cerebral amyloid angiopathy [108]. A recent study prospectively assessed the association between hypertensive disorders of pregnancy (one of the biggest known PRES risk factors in women) and the later development of cognitive impairment 15 years later, demonstrating an association with poorer working memory and verbal learning [109].

In a literature review combining prospective, retrospective, and case-report studies, out of 214 patients diagnosed with RCVS, $61 \%$ reported no cognitive impairment in the long-term, and $31 \%$ reported minor cognitive issues [110]. More studies are needed to evaluate for potential long-term cognitive impairments related to PRES and RCVS specifically, relative to the associated risk.

\section{Sickle Cell Disease (SCD)-Related Headache}

Neurologic complications of SCD include stroke (prevalence of $4.6 \%$ ), abnormal cerebral blood flow (10.6\%), seizures (4.4\%), headaches (17.8-43.9\%), and cognitive impairment ("rare" to 50\%) [111].

The most common headache phenotypes in patients with SCD are tension-type headaches and migraine. The headaches in patients with SCD seem to correlate with high transcranial doppler velocities and low hematocrit [112]. Headaches in patients with SCD could be a sign of stroke, cerebral venous sinus thrombosis, MMA, or posterior PRES.

The main cognitive impairments associated with SCD are processing speed and executive function. In a crosssectional study of 149 patients with SCD compared to 47 healthy controls, SCD was associated with worse intellectual quotients, working memory, processing speed, and executive function [113]. A retrospective study of 83 patients and 32 sibling controls shows that patients with SCD have lower processing speed regardless of silent infarct burden on MRI [114]. In a survey study, 2436 participants with SCD selfreported deficits in attention (55\%), executive functioning $(51 \%)$, processing speed (57\%), and reading comprehension (65\%) [115]. In a cross-sectional study of 252 patients with SCD of mean age 35 years, $11.5 \%$ had Rowland Universal Dementia Assessment Scale (RUDAS) scores suggestive of dementia, with the limitation of the very young participant age to assess for dementia [116]. The RUDAS scores were also unsurprisingly associated with age, kidney function, disease severity [116].

Regarding the pathophysiology for this association, a meta-analysis reported (1) a positive association between hemoglobin and hematocrit levels and IQ and (2) a negative association between transcranial Doppler velocity and 
visual-spatial and perceptual reasoning [117]. Silent brain infarcts in SCD are associated with cognitive impairment and are common: they affect $39 \%$ of children by 18 years of age and more than half of patients by 30 years of age [118]. To date, there are no standard proven strategies to prevent or improve the cognitive impairment associated with SCD $[119,120]$. However, the American Society of Hematology recommends stroke screening and prevention, cognitive impairment screening, and rehabilitation as needed [118]. Early intervention is crucial as SCD-related cognitive deficits impact education levels, unemployment, and instrumental activities of daily living [115, 121].

\section{Post-Concussion Symptoms}

There are no specific phenotypes for post-traumatic headaches, but they frequently resemble migraine and tensiontype headaches [122]. Headaches are amongst the most disabling and longest-lasting symptoms of the post-concussion syndrome [123-125]. However, post-traumatic headaches gradually resolve over time in most patients [126]. The prevalence of headaches 3 months after traumatic brain injury is between 47 and 78\% [127, 128]. In a prospective study of 235 patients with mild traumatic brain injury (TBI), 36\% of participants reported headaches at 6 months post-injury [129]. Post-traumatic headaches (PTH) are noticed late in the course of severe traumatic brain injury once there has already been some recovery, while post-traumatic headaches are present early in the course of mild traumatic brain injury [130].

PTH is associated with poorer neuropsychological testing scores and increased severity of somatic complaints, which is a predictor of prolonged recovery [131-134]. Post-concussive symptoms, including PTH, are associated with cognitive dysfunction, especially in attention, memory, and processing speed early in the post-traumatic course. Given the multitude of post-concussion symptoms, it is methodologically difficult to tease out the specific association between PTH and cognition. In a prospective cohort study of 138 male high school football players with a mean age of 16 years old, the participants with post-traumatic migraine-like headaches performed worse on memory and processing speed tests during the second week post-concussion compared to the participants without the headache and those with post-traumatic nonmigraine-like headaches [135]. A retrospective observational study of 122 athletes with a mean age of 19 years found that PTH was associated with worse performance in overall cognitive, memory, attention, and processing tests adjusting for baseline cognitive function and other post-concussion symptoms [136]. In a case-control study of 100 patients with persistent PTH attributed to mild TBI and 100 healthy controls without a history of TBI, PTH was associated with increased risk of poor sleep quality ( 85 vs $42 \%$ ), anxiety (52 vs $8 \%$ ), depression (42 vs $2 \%$ ), and mild cognitive impairment assessed with the MoCA (27\%) [137]. However, the study did not include participants with mild TBI without PTH [137]. The observed association between PTH and sleep disturbances is consistent with prior studies and contributes to worse performance on memory testing $[136,138]$. However, there is conflicting data on a potential association between PTH and post-traumatic depression [139-141].

When suspecting post-traumatic cognitive and/or behavioral impairments, it is helpful to refer patients for neuropsychological testing [142]. Once the domains affected are identified, neurocognitive rehabilitation can help improve some cognitive processes and/or help patients develop strategies to compensate for the posttraumatic cognitive impairments [143-145]. There is evidence that goal management training can help with attention and executive functions [144]. Compensatory cognitive interventions include smartphone reminders, checklists, self-talk when completing complex tasks [144]. Posttraumatic neurocognitive rehabilitation is recommended after moderate to severe traumatic brain injury (TBI) and after mild traumatic brain injury if cognitive impairments persist more than 4 weeks after sportsrelated TBI or more than 3 months after non-sports TBI [144].

In summary, post-traumatic headaches are disabling, long-lasting, and associated with poorer neuropsychological testing scores and increased severity of somatic complaints. However, there is no evidence currently those post-traumatic headaches are associated with cognitive impairment in the long term.

\section{Frontotemporal Brain Sagging Syndrome (FBSS), a Spontaneous Intracranial Hypotension Syndrome Mimicking Frontotemporal Dementia}

Frontotemporal brain sagging syndrome refers to the combination of clinical behavioral variant frontotemporal dementia and radiographic evidence of brain sagging [146]. The headaches associated with this disorder are often described as postural [147-149]. In a small retrospective chart review, 8 patients with a mean age of onset of 53 years old presented with the insidious progression of behavioral changes (disinhibition and apathy), mild cognitive and executive deficits, and daytime somnolence [146]. None of the patients had radiographic evidence of frontotemporal atrophy on MRI. The patients all developed headaches either before or at the onset of the cognitive changes [146].

Brain imaging with attention to looking for the stigmata of spontaneous intracranial hypotension should be considered in 
patients with clinical evidence of behavioral variant frontotemporal dementia who complain of a postural headache to evaluate for FBSS as it might be at least temporarily improved with a blood patch, high dose steroids, and/or repair of CSF leaks $[146,150]$.

\section{Idiopathic Intracranial Hypertension (IIH)}

Although cognitive impairment had been described as comorbidity associated with IIH in 1986, recent research has highlighted the risk factors and characteristics of cognitive impairment in IIH $[151 \bullet$, 152]. Patients with IIH have impairments of attention, language, memory, processing speed, executive function, and visuospatial skills [151•, 153-155]. Risk factors for developing cognitive impairment in IIH include headache, depression, high serum cortisol levels, and obstructive sleep apnea $[151 \bullet, 156]$. Obesity is not $[151 \bullet]$. Interestingly, the IIH-associated cognitive impairments seem to be reversible with treatment that reduces intracranial pressure, such as carbonic anhydrase inhibitors and ventriculoperitoneal shunt placement [153, 157]. Grech et al. demonstrated that in patients with IIH, response time is significantly reduced after lumbar puncture indicating an immediate improvement in attention after reducing the intracranial pressure [151•].

\section{Limitations}

There is significant heterogeneity in the cognitive tests used in the studies. To our knowledge, there is no standardized validated test for interictal cognitive assessment of young adults with headache diseases. The rapid tests such as the Montreal Cognitive Assessment or Mini-Mental State Exam, for example, were not validated for this population. As a result, the authors cannot recommend a specific cognitive test to use based on current data.

Table 1 Summary of headache diseases and cognitive function

\begin{tabular}{|c|c|c|}
\hline Headache disease & Headache semiology & Cognitive function \\
\hline Migraine & & $\begin{array}{l}\text { - Early deficits in verbal comprehension, attention, and } \\
\text { school grades before the onset of attacks } \\
\text { - Interictal deficits in attention, calculation, executive func- } \\
\text { tion, language, psychomotor speed, visuospatial skills, } \\
\text { and memory in the first part of life } \\
\text { - Unlikely to be associated with dementia }\end{array}$ \\
\hline Tension-type headache & & - No clear association with cognitive deficits \\
\hline Cluster headache & & - Some evidence for executive deficits \\
\hline CADASIL & - Migraine with aura like & $\begin{array}{l}\text { - Deficits in executive function, attention, psychomotor } \\
\text { speed, and visuospatial skills }\end{array}$ \\
\hline MELAS & $\begin{array}{l}\text { - Recurrent migraine-like attacks } \\
\text { - Acute headache preceding or associated with focal } \\
\text { neurological deficits and/or seizures }\end{array}$ & $\begin{array}{l}\text { - Deficits in executive function, attention, visuospatial } \\
\text { skills }\end{array}$ \\
\hline CAA & - Migraine-aura-like episodes & - Cognitive decline \\
\hline CAA-ri & - No specific phenotype & $\begin{array}{l}\text { - Cognitive decline in orientation, attention, episodic } \\
\text { memory, personality, and/or behavioral changes }\end{array}$ \\
\hline RVCLSM & - Migraine-like headaches usually without aura & $\begin{array}{l}\text { - Bradyphrenia, apathy, irritability, impairments in } \\
\text { memory, and judgment }\end{array}$ \\
\hline MMA & - No specific phenotype & $\begin{array}{l}\text { - Deficits in memory, processing speed, attention, executive } \\
\text { function, computational ability, and visuospatial skills }\end{array}$ \\
\hline Giant cell arteritis & $\begin{array}{l}\text { - New onset or different headache after } 50 \text { years of age } \\
\text { with or without scalp tenderness }\end{array}$ & - Abrupt or step-wise confusion $+/-$ multi-infarct dementia \\
\hline SMART syndrome & - Migraine-like headaches & - Confusion, psychomotor slowing, and aphasia \\
\hline PRES and RCVS & - Thunderclap or other headaches & $\begin{array}{l}\text {-Deficits in short-term memory, attention, visuospatial } \\
\text { skills, executive function }\end{array}$ \\
\hline SCD & $\begin{array}{l}\text { - Tension-type headache-like } \\
\text { - Migraine-like headaches }\end{array}$ & $\begin{array}{l}\text { - Deficits in processing speed, executive function, IQ, and } \\
\text { working memory }\end{array}$ \\
\hline PTH & $\begin{array}{l}\text { - Tension-type headache-like } \\
\text { - Migraine-like headaches }\end{array}$ & $\begin{array}{l}\text { - Deficits in overall cognition, memory, attention, and } \\
\text { processing speed } \\
\text { - No strong evidence for long-term cognitive impairments }\end{array}$ \\
\hline FBSS & $\begin{array}{l}\text { - Orthostatic, exertional, "second half of the day," or new } \\
\text { daily persistent headache }\end{array}$ & $\begin{array}{l}\text { - Insidious progression of behavioral changes, mild cogni- } \\
\text { tive impairments, especially in executive function }\end{array}$ \\
\hline IIH & - Headache worse in recumbency with vision changes & $\begin{array}{l}\text { - Deficits in attention, language, memory, processing } \\
\text { speed, executive function, and visuospatial skills }\end{array}$ \\
\hline
\end{tabular}


The mean age of many of the studies discussed is too low to be able to assess for dementia. Worse scores in terms of cognitive function in case-control studies do not necessarily reflect cognitive impairment but a statistically significant difference between the groups. Given the currently growing evidence on post-COVID-19 headaches and post-acute sequelae SARS-CoV-2 infection (PASC), potential associations between post-COVID-19 headaches and PASC cognitive impairment were not discussed in this review.

\section{Conclusion}

Summarizing the literature on headache and cognitive decline is challenging due to the heterogeneity in study designs, participant samples, and cognitive tests. Interestingly, migraine is associated with cognitive impairment and worse school performance years before a migraine diagnosis. In young and middle-aged adults, migraine is associated with deficits in attention, calculation, orientation, executive function, language, psychomotor speed, visuo-constructive skills, and memory. Reassuringly, it seems unlikely that migraine predisposes to dementia. It is plausible that interictal cognitive deficits found in early and mid-adulthood may improve as the natural history of migraine also improves with aging. The more recent appreciation of cogniphobia, a fear and avoidance of cognitive exertion, could also influence cognitive test results among people with migraine even interictally [158]. Cognitive differences between people with and without migraine may attenuate with age as other risk factors for dementia such as cardiovascular risk factors become more prevalent. Further studies are needed to develop interictal cognitive testing and treatment for cognitive dysfunction for young adults with migraine. It would also be helpful to assess whether the sleep disorders comorbid with migraine are associated with objective cognitive impairments.

A few secondary headache syndromes (CADASIL, MELAS, RVCSLM, and cerebral amyloid angiopathy) are associated with a small-vessel disease process and subcortical dementia, which presents mostly with deficits in attention, visuospatial/executive function, and psychomotor speed. It is crucial to recognize the potentially reversible dementias associated with secondary headache disorders such as giant cell arteritis (GCA) and CAA-ri to attempt treatment rapidly. It is important to note that postural headaches tend to be the first symptom of frontotemporal brain sagging syndrome. Brain imaging to look for the stigmata of spontaneous intracranial hypotension should be considered in patients with postural headaches, and a behavioral variant frontotemporal dementia phenotype as FBSS might improve with blood patch and/or repair of CSF leaks.
Table 1 summarizes the findings of this literature review briefly listing the observed cognitive dysfunction for each headache disease discussed.

\section{Compliance with Ethical Standards}

Conflict of Interest Dr. Begasse de Dhaem serves as Section Editor of Headache and Facial Pain for the Pain Medicine editorial board. She also provides education on headache medicine-related topics for the virtual clinic Neura Health. Dr. Robbins serves on the Board of Directors of the American Headache Society, in editorial capacities for Headache and Current Pain and Headache Reports, and receives book royalties from Wiley.

Human and Animal Rights and Informed Consent Not applicable.

\section{References}

Papers of particular interest, published recently, have been highlighted as:

- Of importance

1. Dua T, Seeher KM, Sivananthan S, Chowdhary N, Pot AM, Saxena S. World Health Organization's global action plan on the public health response to dementia 2017-2025. Alzheimer's \& Dementia: The Journal of the Alzheimer's Association. 2017;13:P1450-1.

2. Steiner TJ. Lifting the burden: the global campaign against headache. Lancet Neurol. 2004;3:204-5.

3. Vuralli D, Ayata C, Bolay H. Cognitive dysfunction and migraine. J Headache Pain. 2018;19:109.

4. Gil-Gouveia R, Martins IP. Cognition and cognitive impairment in migraine. Curr Pain Headache Rep. 2019;23:84. This review complements the current review as it describes cognitive dysfunction ictally in migraine and discusses pathophysiologic hypotheses for the association between migraine and cognitive impairment.

5. Waldie KE, Hausmann M, Milne BJ, Poulton R. Migraine and cognitive function: a life-course study. Neurology. 2002;59:904-8.

6. Zeitlin C, Oddy M. Cognitive impairment in patients with severe migraine. Br J Clin Psychol. 1984;23(Pt 1):27-35.

7. Calandre EP, Bembibre J, Arnedo ML, Becerra D. Cognitive disturbances and regional cerebral blood flow abnormalities in migraine patients: their relationship with the clinical manifestations of the illness. Cephalalgia. 2002;22:291-302.

8. Santangelo G, Russo A, Trojano L, Falco F, Marcuccio L, Siciliano M, et al. Cognitive dysfunctions and psychological symptoms in migraine without aura: a cross-sectional study. $\mathrm{J}$ Headache Pain. 2016;17:76.

9. Le Pira F, Zappalà G, Giuffrida S, Lo Bartolo ML, Reggio E, Morana R, et al. Memory disturbances in migraine with and without aura: a strategy problem? Cephalalgia. 2000;20:475-8.

10. Huang L, juan Dong H, Wang X, Wang Y, Xiao Z. Duration and frequency of migraines affect cognitive function: evidence from neuropsychological tests and event-related potentials. J Headache Pain. 2017;18:54.

11. Hooker WD, Raskin NH. Neuropsychologic alterations in classic and common migraine. Arch Neurol. 1986;43:709-12.

12. Santangelo G, Russo A, Tessitore A, Garramone F, Silvestro M, Della Mura MR, et al. Prospective memory is dysfunctional in migraine without aura. Cephalalgia. 2018;38:1825-32.

13. Mongini F, Keller R, Deregibus A, Barbalonga E, Mongini T. Frontal lobe dysfunction in patients with chronic migraine: 
a clinical-neuropsychological study. Psychiatry Res. 2005; 133:101-6.

14. Camarda C, Monastero R, Pipia C, Recca D, Camarda R. Interictal executive dysfunction in migraineurs without aura: relationship with duration and intensity of attacks. Cephalalgia. 2007;27:1094-100.

15. Mulder EJCM, Linssen WHJP, Passchier J, Orlebeke JF, De Geus EJC. Interictal and postictal cognitive changes in migraine. Cephalalgia. 1999;19:557-67.

16. Braganza DL, Fitzpatrick LE, Nguyen ML, Crowe SF. Interictal cognitive deficits in migraine sufferers: a meta-analysis. Neuropsychol Rev. 2021. This is an informative meta-analysis describing 17 articles that evaluated potential association between migraine and cognitive dysfunction interictally. It provides a summary of what was known on the topic until January 2020.

17. Pellegrino Baena C, Goulart AC, Santos IS, Suemoto CK, Lotufo PA, Bensenor IJ. Migraine and cognitive function: baseline findings from the Brazilian longitudinal study of adult health: ELSABrasil. Cephalalgia. 2018;38:1525-34.

18. Martins IP, Gil-Gouveia R, Silva C, Maruta C, Oliveira AG. Migraine, headaches, and cognition. Headache. 2012;52:1471-82.

19. Latysheva N, Filatova E, Osipova D, Danilov AB. Cognitive impairment in chronic migraine: a cross-sectional study in a clinic-based sample. Arq Neuropsiquiatr. 2020.

20. Lo Buono V, Bonanno L, Corallo F, Palmeri R, Allone C, Lo Presti R, et al. Cognitive functions and psychological symptoms in migraine: a study on patients with and without aura. International Journal of Neuroscience. United Kingdom: Taylor \& Francis. 2019;129:588-92.

21. Su M, Wang R, Dong Z, Zhao D, Yu S. Decline in attentional inhibition among migraine patients: an event-related potential study using the Stroop task. J Headache Pain. 2021;22:34.

22. Mazzucchi A, Sinforiani E, Zinelli P, Agostinis C, Granella F, Miari A, et al. Interhemispheric attentional functioning in classic migraine subjects during paroxysmal and interparoxysmal phases. Headache: J Head and Face Pain. 1988;28:488-93.

23. Leijdekkers MLA, Passchier J, Goudswaard P, Menges LJ, Orlebeke JF. Migraine patients cognitively impaired? Headache: J Head and Face Pain. 1990;30:352-8.

24. Lo Buono V, Bonanno L, Corallo F, Pisani LR, Lo Presti R, Grugno R, et al. Functional connectivity and cognitive impairment in migraine with and without aura. Journal of Headache and Pain. 2017;18:72.

25. Baschi R, Monastero R, Cosentino G, Costa V, Giglia G, Fierro $\mathrm{B}$, et al. Visuospatial learning is fostered in migraine: evidence by a neuropsychological study. Neurol Sci. 2019.

26. Bashir A, Lipton RB, Ashina S, Ashina M. Migraine and structural changes in the brain: a systematic review and meta-analysis. Neurology. 2013;81:1260-8.

27. Palm-Meinders IH, Koppen H, Terwindt GM, Launer LJ, Konishi J, Moonen JM, et al. Structural brain changes in migraine. JAMA. 2012;308:1889-97.

28. Chuang CS, Lin CL, Lin MC, Sung FC, Kao CH. Migraine and risk of dementia: a nationwide retrospective cohort study. Neuroepidemiology. 2013;41:139-45.

29. Tzeng NS, Chung CH, Lin FH, Yeh CB, Huang SY, Lu RB, et al. Headaches and risk of dementia. Am J Med Sci. 2017;353:197-206.

30. Lee SY, Lim JS, Oh DJ, Kong IG, Choi HG. Increased risk of neurodegenerative dementia in women with migraines: a nested case-control study using a national sample cohort. Medicine (Baltimore). 2019;98:e14467.

31. Morton RE, St. John PD, Tyas SL. Migraine and the risk of allcause dementia, Alzheimer's disease, and vascular dementia: a prospective cohort study in community-dwelling older adults. Int J Geriatr Psychiatry. 2019.
32. Kostev K, Bohlken J, Jacob L. Association between migraine headaches and dementia in more than 7,400 patients followed in general practices in the United Kingdom. J Alzheimer's Dis. 2019.

33. Rist PM, Kang JH, Buring JE, Glymour MM, Grodstein F, Kurth T. Migraine and cognitive decline among women: prospective cohort study. BMJ. 2012;345:e5027.

34. Wen K, Nguyen NT, Hofman A, Ikram MA, Franco OH. Migraine is associated with better cognition in the middle-aged and elderly: the Rotterdam Study. Eur J Neurol. 2016;23:1510-6.

35. Kalaydjian A, Zandi PP, Swartz KL, Eaton WW, Lyketsos C. How migraines impact cognitive function: findings from the Baltimore ECA. Neurology. 2007;68:1417-24.

36. Røttereng AKS, Bosnes O, Stordal E, Zwart J-A, Linde M, Stovner LJ, et al. Headache as a predictor for dementia: the HUNT Study. J Headache Pain. 2015;16:89.

37. Hagen K, Stordal E, Linde M, Steiner TJ, Zwart J-A, Stovner LJ. Headache as a risk factor for dementia: a prospective populationbased study. Cephalalgia. 2014;34:327-35.

38. Jelicic M, Van Boxtel MPJ, Houx PJ, Jolles J. Does migraine headache affect cognitive function in the elderly? Report from the Maastricht Aging Study (MAAS). Headache: J Head and Face Pain. 2000;40:715-9.

39. Baars MAE, Van Boxtel MPJ, Jolles J. Migraine does not affect cognitive decline: results from the maastricht aging study: Research submission. Headache. 2010;50:176-84.

40. George KM, Folsom AR, Sharrett AR, Mosley TH, Gottesman RF, Hamedani AG, et al. Migraine headache and risk of dementia in the atherosclerosis risk in communities neurocognitive study. Headache. 2020.

41. Martins IP, Maruta C, Alves PN, Loureiro C, Morgado J, Tavares $\mathrm{J}$ G-GR. Cognitive aging in migraine sufferers is associated with more subjective complaints but similar age-related decline: a 5-year longitudinal study. J Headache Pain. 2020;21:31.

42. Migraine, cognitive decline, and dementia in older adults: a population-based study. Headache Journal. In press. It concisely lists the prior important articles related to the topic of migraine and dementia risk and presents the latest data on the topic: a cross-sectional and longitudinal populationbased study that did not find an association between migraine and dementia.

43. Kurth T, Mohamed S, Maillard P, Zhu YC, Chabriat H, Mazoyer $\mathrm{B}$, et al. Headache, migraine, and structural brain lesions and function: population based epidemiology of vascular ageingMRI study. BMJ. 2011;342:c7357.

44. Gaist D, Pedersen L, Madsen C, Tsiropoulos I, Bak S, Sindrup S, et al. Long-term effects of migraine on cognitive function: a population-based study of Danish twins. Neurology. 2005;64:600-7.

45. Pearson AJ, Chronicle EP, Maylor EA, Bruce LAM. Cognitive function is not impaired in people with a long history of migraine: a blinded study. Cephalalgia. 2006;26:74-80.

46. Karner E, Delazer M, Benke T, Bosch S. Cognitive functions, emotional behavior, and quality of life in familial hemiplegic migraine. Cogn Behav Neurol. 2010;23:106-11.

47. Karner E, Nachbauer W, Bodner T, Benke T, Boesch S, Delazer $\mathrm{M}$. Long-term outcome of cognitive functions, emotional behavior, and quality of life in a family with familial hemiplegic migraine. Cogn Behav Neurol. 2012;25:85-92.

48. Wang P, Yang Y-R, Zhang H-B, Wang J-H, Wang Y. Cognitive dysfunction in a patient with migraine and APT1A2 mutation: a case report. Neurol Sci [Internet]. 2021. Available from:https:// doi.org/10.1007/s10072-021-05284-1

49. Humbertclaude V, Riant F, Krams B, Zimmermann V, Nagot $\mathrm{N}$, Annequin $\mathrm{D}$, et al. Cognitive impairment in children with CACNA1A mutations. Dev Med Child Neurol. 2020;62:330-7. 
50. Rasmussen BK, Jensen R, Schroll M, Olesen J. Epidemiology of headache in a general population--a prevalence study. J Clin Epidemiol. 1991;44:1147-57.

51. Waldie KE, Welch D. Cognitive function in tension-type headache. Curr Pain Headache Rep. 2007;11:454-60.

52. Yang FC, Lin TY, Chen HJ, Lee JT, Lin CC, Kao CH. Increased risk of dementia in patients with tension-type headache: a nationwide retrospective population-based cohort study. PLoS One. 2016;11:e0156097.

53. Qu P, Yu J, Xia L, Chen G. Cognitive performance and the alteration of neuroendocrine hormones in chronic tension-type headache. Pain Pract. 2018;18:8-17.

54. Dresler T, Lurding R, Paelecke-Habermann Y, Gaul C, Henkel $\mathrm{K}$, Lindwurm-Spath A, et al. Cluster headache and neuropsychological functioning. Cephalalgia. 2012;32:813-21.

55. Santos-Lasaosa S, Bellosta-Diago E, Lopez-Bravo A, ViloriaAlebesque A, Garrido-Fernandez A, Pilar Navarro-Perez M. Cognitive performance in episodic cluster headache. Pain Med. 2019;20:1032-7.

56. Cognitive performance in patients with episodic cluster headache outside and inside the active cluster. 2021. Available from: https://headachejournal.onlinelibrary.wiley.com/doi/ 10.1111/head.14052.

57. Wang MM. Cadasil. Handbook of clinical neurology. Elsevier. 2018:733-43.

58. Dichgans M, Mayer M, Uttner I, Bruning R, Muller-Hocker J, Rungger G, et al. The phenotypic spectrum of CADASIL: clinical findings in 102 cases. Ann Neurol. 1998;44:731-9.

59. Roine S, Pöyhönen M, Timonen S, Tuisku S, Marttila R, Sulkava R, et al. Neurologic symptoms are common during gestation and puerperium in CADASIL. Neurology. 2005;64:1441-3.

60. Glover RL, Vollbracht S, Robbins MS. Acute postpartum headache. Headache. 2014;54:1073-84.

61. Headache Classification Committee of the International Headache Society (IHS). The International Classification of Headache Disorders, 3rd edition. Cephalalgia. 2018;38:1-211.

62. Jokinen H, Gouw AA, Madureira S, Ylikoski R, van Straaten EC, van der Flier WM, et al. Incident lacunes influence cognitive decline: the LADIS study. Neurology. 2011;76:1872-8.

63. Zhang Q, Wang D, Wu S, Ren Y, Li Y, Zhang J, et al. Diffuse tract damage correlates with global cognitive impairment in cerebral autosomal dominant arteriopathy with subcortical infarcts and leukoencephalopathy: a tract-based spatial statistics study. J Comput Assist Tomogr. 2021;45:285-93.

64. Jacobs HIL, Schoemaker D, Torrico-Teave H, Zuluaga Y, Velilla-Jimenez L, Ospina-Villegas C, et al. Specific abnormalities in white matter pathways as interface to small vessels disease and cognition in cerebral autosomal dominant arteriopathy with subcortical infarcts and leukoencephalopathy individuals. Brain Connect. 2021.

65. Tábuas-Pereira M, Varela R, Beato-Coelho J, Maleita D, Ferreira $\mathrm{C}$, d'Almeida OC, et al. Headache intensity is associated with increased white matter lesion burden in CADASIL patients. $\mathbf{J}$ Clin Neurosci. 2020.

66. Opherk C, Peters N, Herzog J, Luedtke R, Dichgans M. Longterm prognosis and causes of death in CADASIL: a retrospective study in 411 patients. Brain. 2004;127:2533-9.

67. Dichgans M, Markus HS, Salloway S, Verkkoniemi A, Moline $\mathrm{M}$, Wang Q, et al. Donepezil in patients with subcortical vascular cognitive impairment: a randomised double-blind trial in CADASIL. Lancet Neurol. 2008;7:310-8.

68. Majamaa-Voltti KA, Winqvist S, Remes AM, Tolonen U, Pyhtinen J, Uimonen S, et al. A 3-year clinical follow-up of adult patients with $3243 \mathrm{~A}>\mathrm{G}$ in mitochondrial DNA. Neurology. 2006;66:1470-5.
69. Kraya T, Neumann L, Paelecke-Habermann Y, Deschauer M, Stoevesandt D, Zierz S, et al. Cognitive impairment, clinical severity and MRI changes in MELAS syndrome. Mitochondrion. 2019;44:53-7.

70. El-Hattab AW, Almannai M, Scaglia F. Arginine and citrulline for the treatment of MELAS syndrome. J Inborn Errors Metab Screen. SAGE Publications Inc. 2017;5:2326409817697399.

71. De Luca R, Russo M, Leonardi S, Spadaro L, Cicero C, Naro A, et al. Advances in the treatment of MELAS syndrome: could cognitive rehabilitation have a role? Appl Neuropsychol Adult. 2016;23:61-4.

72. Vinters HV. Cerebral amyloid angiopathy. A critical review. Stroke. 1987; 18:311-24.

73. Greenberg SM, Vonsattel JPG, Stakes JW, Gruber M, Finklestein SP. The clinical spectrum of cerebral amyloid angiopathy: presentations without lobar hemorrhage. Neurology. 1993;43:2073.

74. Auriel E, Charidimou A, Gurol ME, Ni J, Van Etten ES, MartinezRamirez S, et al. Validation of clinicoradiological criteria for the diagnosis of cerebral amyloid angiopathy-related inflammation. JAMA Neurol. 2016;73:197-202.

75. Kinnecom C, Lev MH, Wendell L, Smith EE, Rosand J, Frosch MP, et al. Course of cerebral amyloid angiopathy-related inflammation. Neurology. 2007;68:1411-6.

76. Eng JA, Frosch MP, Choi K, Rebeck GW, Greenberg SM. Clinical manifestations of cerebral amyloid angiopathy-related inflammation. Ann Neurol. 2004;55:250-6.

77. Chung KK, Anderson NE, Hutchinson D, Synek B, Barber PA. Cerebral amyloid angiopathy related inflammation: three case reports and a review. J Neurol Neurosurg Psychiatry. 2011;82:20-6.

78. Beaman CB, Spagnolo-Allende A, Lin C-C. Headache, cognitive decline, and a curious rim-enhancing lesion. JAMA Neurol. 2021;78:613-4.

79. Wu J-J, Yao M, Ni J. Cerebral amyloid angiopathy-related inflammation: current status and future implications. Chin Med J (Engl). 2021;134:646-54. This article provides a thorough introduction and presentation of an important entity to recognize for Neurologists and Headache Specialists.

80. Castro Caldas A, Silva C, Albuquerque L, Pimentel J, Silva V, Ferro JM. Cerebral Amyloid angiopathy associated with inflammation: report of 3 cases and systematic review. J Stroke Cerebrovasc Dis. 2015;24:2039-48.

81. Regenhardt RW, Thon JM, Das AS, Thon OR, Charidimou A, Viswanathan A, et al. Association between immunosuppressive treatment and outcomes of cerebral amyloid angiopathyrelated inflammation. JAMA Neurol. 2020;77:1-10.

82. Stam AH, Kothari PH, Shaikh A, Gschwendter A, Jen JC, Hodgkinson S, et al. Retinal vasculopathy with cerebral leukoencephalopathy and systemic manifestations. Brain. 2016;139:2909-22.

83. de Boer I, Pelzer N, Terwindt G. Retinal vasculopathy with cerebral leukoencephalopathy and systemic manifestations. In: Adam MP, Ardinger HH, Pagon RA, Wallace SE, Bean LJ, Gripp KW, et al., editors. GeneReviews ${ }^{\circledR}$ [Internet]. Seattle (WA): University of Washington, Seattle; 1993 [cited 2022 Jan 11]. Available from: http://www.ncbi.nlm.nih.gov/books/NBK546576/

84. Zach V, Bezov D, Lipton RB, Ashina S. Headache associated with moyamoya disease: a case story and literature review. J Headache Pain. 2010;11:79-82.

85. Tozzi E, Antenucci A, Di Loreto S, Maresca M, Farello G, Massimi L. Moyamoya disease and headache: case report. J Headache Pain. 2015;16:1.

86. Ezura M, Yoshimoto T, Fujiwara S, Takahashi A, Shirane R, Mizoi K. Clinical and angiographic follow-up of childhoodonset moyamoya disease. Childs Nerv Syst. 1995;11:591-4.

87. Kurokawa T, Tomita S, Ueda K, Narazaki O, Hanai T, Hasuo K, et al. Prognosis of occlusive disease of the circle 
of Willis (moyamoya disease) in children. Pediatr Neurol. $1985 ; 1: 274-7$.

88. Kronenburg A, van den Berg E, van Schooneveld MM, Braun KPJ, Calviere L, van der Zwan A, et al. Cognitive functions in children and adults with moyamoya vasculopathy: a systematic review and meta-analysis. J Stroke. 2018;20:332-41.

89. Nakamizo A, Amano T, Michiwaki Y, Kawano Y, Kuwashiro $\mathrm{T}$, Yasaka $\mathrm{M}$, et al. Long-term neurocognitive outcomes in patients with adult Moyamoya disease. World Neurosurg. 2018;119:e441-8.

90. He S, Liu Z, Wei Y, Duan R, Xu Z, Zhang C, et al. Impairments in brain perfusion, executive control network, topological characteristics, and neurocognition in adult patients with asymptomatic Moyamoya disease. BMC Neurosci. 2021;22:35.

91. He S, Duan R, Liu Z, Ye X, Yuan L, Li T, et al. Characteristics of cognitive impairment in adult asymptomatic moyamoya disease. BMC Neurol. 2020;20:322.

92. Smith JH, Swanson JW. Giant cell arteritis. Headache. 2014;54:1273-89.

93. Hunder GG, Bloch DA, Michel BA, Stevens MB, Arend WP, Calabrese LH, et al. The American College of Rheumatology 1990 criteria for the classification of giant cell arteritis. Arthritis Rheum. 1990;33:1122-8.

94. Caselli RJ, Hunder GG, Whisnant JP. Neurologic disease in biopsy-proven giant cell (temporal) arteritis. Neurology. 1988;38:352.

95. Caselli RJ, Hunder GG. Giant cell (temporal) arteritis. Neurol Clin. 1997;15:893-902.

96. Caselli RJ. Giant cell (temporal) arteritis: a treatable cause of multi-infarct dementia. Neurology. 1990;40:753-5.

97. Solans-Laqué R, Bosch-Gil JA, Molina-Catenario CA, Ortega-Aznar A, Alvarez-Sabin J, Vilardell-Tarres M. Stroke and multi-infarct dementia as presenting symptoms of giant cell arteritis: report of 7 cases and review of the literature. Medicine. 2008;87:335-44.

98. Pauls M, Singh M, Martin P. An unusual case of giant cell arteritis. Pract Neurol. 2021;21:228-30.

99. Lahaye C, Sanchez M, Rouet A, Gross A, Faucher N, RaynaudSimon A, et al. A curable pseudo-dementia related to an atypical presentation of giant cell arteritis. Age Ageing. 2020;49:487-9.

100. Hajj-Ali RA, Singhal AB, Benseler S, Molloy E, Calabrese LH. Primary angiitis of the CNS. Lancet Neurol. 2011;10:561-72.

101. Dominguez M, Malani R. Stroke-like migraine attacks after radiation therapy (SMART) syndrome: a comprehensive review. Curr Pain Headache Rep. 2021;25:33.

102. Di Stefano AL, Berzero G, Ducray F, Eoli M, Pichiecchio A, Farina LM, et al. Stroke-like events after brain radiotherapy: a large series with long-term follow-up. Eur J Neurol. 2019;26:639-50.

103. Kerklaan JP, á Nijeholt GJL, Wiggenraad RGJ, Berghuis B, Postma TJ, Taphoorn MJB. SMART syndrome: a late reversible complication after radiation therapy for brain tumours. $\mathbf{J}$ Neurol. 2011;258:1098-104.

104. Black DF, Morris JM, Lindell EP, Krecke KN, Worrell GA, Bartleson JD, et al. Stroke-like migraine attacks after radiation therapy (SMART) syndrome is not always completely reversible: a case series. Am J Neuroradiol. 2013;34:2298-303.

105. Chen SP, Fuh JL, Lirng JF, Chang FC, Wang SJ. Recurrent primary thunderclap headache and benign CNS angiopathy: spectra of the same disorder? Neurology. 2006;67:2164-9.

106. Stroescu I, Salinas CM, Nahab FB, Stringer AY. Long-term neurocognitive and neuroimaging outcomes in posterior reversible encephalopathy syndrome: two case reports and implications. Clin Neuropsychol. 2011;25:1386-402.

107. Seemiller J, Malik MT. Cognitive sequelae of central-variant posterior reversible encephalopathy syndrome (PRES). Case Rep Neurol Med. 2021;2021:8850316.
108. Ros Forteza FJ. Alzheimer disease triggered by reversible posterior leukoencephalopathy syndrome. Neurologia. 2018.

109. Adank MC, Hussainali RF, Oosterveer LC, Ikram MA, Steegers EAP, Miller EC, et al. Hypertensive disorders of pregnancy and cognitive impairment: a prospective cohort study. Neurology. 2021;96:e709-18.

110. Sattar A, Manousakis G, Jensen MB. Systematic review of reversible cerebral vasoconstriction syndrome. Expert Rev Cardiovasc Ther. 2010;8:1417-21.

111. Noubiap JJ, Mengnjo MK, Nicastro N, Kamtchum-Tatuene J. Neurologic complications of sickle cell disease in Africa: a systematic review and meta-analysis. Neurology. 2017;89:1516-24.

112. Silva GS, Vicari P, Figueiredo MS, Junior HC, Idagawa MH, Massaro AR. Migraine-mimicking headache and sickle cell disease: a transcranial Doppler study. Cephalalgia. 2006;26:678-83.

113. Vichinsky EP, Neumayr LD, Gold JI, Weiner MW, Rule RR, Truran D, et al. Neuropsychological dysfunction and neuroimaging abnormalities in neurologically intact adults with sickle cell anemia. JAMA. 2010;303:1823-31.

114. Stotesbury H, Kirkham FJ, Kolbel M, Balfour P, Clayden JD, Sahota $\mathrm{S}$, et al. White matter integrity and processing speed in sickle cell anemia. Neurology. 2018;90:e2042-50.

115. Longoria JN, Pugh NL, Gordeuk V, Hsu LL, Treadwell M, King AA, et al. Patient-reported neurocognitive symptoms influence instrumental activities of daily living in sickle cell disease. Am J Hematol. 2021;96:1396-406.

116. Forté S, Blais F, Castonguay M, Fadiga N, Fortier-St-Pierre M, Couette M, et al. Screening for cognitive dysfunction using the Rowland Universal Dementia Assessment Scale in adults with sickle cell disease. JAMA Netw Open. 2021;4:e217039.

117. Prussien K V., Siciliano RE, Ciriegio AE, Anderson AS, Sathanayagam R, Debaun MR, et al. Correlates of cognitive function in sickle cell disease: a meta-analysis. J Pediatr Psychol. 2020.

118. DeBaun MR, Jordan LC, King AA, Schatz J, Vichinsky E, Fox CK, et al. American Society of Hematology 2020 guidelines for sickle cell disease: prevention, diagnosis, and treatment of cerebrovascular disease in children and adults. Blood Adv. 2020.

119. Strouse J. Sickle cell disease. Handbook of clinical neurology. Elsevier. 2016:311-24.

120. Hyacinth HI, Idris IM. Cognitive deficit in sickle cell disease: is hydroxyurea part of the story? Br J Haematol. 2020.

121. Sanger M, Jordan L, Pruthi S, Day M, Covert B, Merriweather $\mathrm{B}$, et al. Cognitive deficits are associated with unemployment in adults with sickle cell anemia. J Clin Exp Neuropsychol. 2016;38:661-71.

122. Katz DI, Cohen SI, Alexander MP. Mild traumatic brain injury. Handbook of clinical neurology. Elsevier. 2015:131-56.

123. Polinder S, Cnossen MC, Real RGL, Covic A, Gorbunova A, Voormolen DC, et al. A multidimensional approach to postconcussion symptoms in mild traumatic brain injury. Front Neurol. 2018;9:1113.

124. Conidi FX. Interventional treatment for post-traumatic headache. Curr Pain Headache Rep. 2016;20:40.

125. Minen M, Jinich S, Vallespir Ellett G. Behavioral therapies and mind-body interventions for posttraumatic headache and post-concussive symptoms: a systematic review. Headache. 2019;59:151-63.

126. Cushman DM, Borowski L, Hansen C, Hendrick J, Bushman T, Teramoto M. Gabapentin and tricyclics in the treatment of postconcussive headache, a retrospective cohort study. Headache. 2019;59:371-82.

127. Rimel RW, Giordani B, Barth JT, Boll TJ, Jane JA. Disability caused by minor head injury. Neurosurgery. 1981;9:221-8. 
128. Levin HS, Mattis S, Ruff RM, Eisenberg HM, Marshall LF, Tabaddor K, et al. Neurobehavioral outcome following minor head injury: a three-center study. J Neurosurg. 1987;66:234-43.

129. Kraus J, Schaffer K, Ayers K, Stenehjem J, Shen H, Afifi AA. Physical complaints, medical service use, and social and employment changes following mild traumatic brain injury: a 6-month longitudinal study. J Head Trauma Rehabil. 2005;20:239-56.

130. Formisano R, Bivona U, Catani S, D'Ippolito M, Buzzi MG. Post-traumatic headache: facts and doubts. J Headache Pain. 2009;10:145-52.

131. Collins MW, Field M, Lovell MR, Iverson G, Johnston KM, Maroon J, et al. Relationship between postconcussion headache and neuropsychological test performance in high school athletes. Am J Sports Med. 2003;31:168-73.

132. Gunstad J, Suhr JA. Cognitive factors in postconcussion syndrome symptom report. Arch Clin Neuropsychol. 2004;19:391-405.

133. De Dhaem OB, Barr WB, Balcer LJ, Galetta SL, Minen MT. Post-traumatic headache: the use of the sport concussion assessment tool (SCAT-3) as a predictor of post-concussion recovery. J Headache Pain. 2017;18:60.

134. Meehan WP III, Mannix RC, Stracciolini A, Elbin RJ, Collins MW. Symptom severity predicts prolonged recovery after sport-related concussion, but age and amnesia do not. J Pediatr. 2013;163:721-5.

135. Oyegbile TO, Dougherty A, Tanveer S, Zecavati N, Delasobera BE. High sleep disturbance and longer concussion duration in repeat concussions. Behav Sleep Med. 2020;18:241-8.

136. Guty E, Arnett P. Post-concussion symptom factors and neuropsychological outcomes in collegiate athletes. J Int Neuropsychol Soc. 2018;24:684-92.

137. Ashina H, Al-Khazali HM, Iljazi A, Ashina S, Amin FM, Lipton $\mathrm{RB}$, et al. Psychiatric and cognitive comorbidities of persistent post-traumatic headache attributed to mild traumatic brain injury. J Headache Pain. 2021;22:83.

138. Kim S-K, Chong CD, Dumkrieger G, Ross K, Berisha V, Schwedt TJ. Clinical correlates of insomnia in patients with persistent post-traumatic headache compared with migraine. J Headache Pain. 2020;21:33.

139. Kumar RG, Gao S, Juengst SB, Wagner AK, Fabio A. The effects of post-traumatic depression on cognition, pain, fatigue, and headache after moderate-to-severe traumatic brain injury: a thematic review. Brain Inj. 2018;32:383-94.

140. McMurtray AM, Saito EK, Diaz N, Mehta B, Nakamoto B. Greater frequency of depression associated with chronic primary headaches than chronic post-traumatic headaches. Int $\mathbf{J}$ Psychiatry Med. 2013;45:227-36.

141. Khan F, Amatya B, Judson R, Chung P, Truesdale M, Elmalik A, et al. Factors associated with long-term functional and psychological outcomes in persons with moderate to severe traumatic brain injury. J Rehabil Med. 2016;48:442-8.

142. Jordan BD. Chronic traumatic encephalopathy and other longterm sequelae. Continuum: Lifelong Learning in Neurology. 2014;20:1588.

143. Leddy JJ, Sandhu H, Sodhi V, Baker JG, Willer B. Rehabilitation of concussion and post-concussion syndrome. Sports Health. 2012;4:147-54
144. Marklund N, Bellander B-M, Godbolt A, Levin H, McCrory P, Thelin EP. Treatments and rehabilitation in the acute and chronic state of traumatic brain injury. J Intern Med. 2019;285:608-23.

145. Freire FR, Coelho F, Lacerda JR, da Silva MF, Gonçalves VT, Machado S, et al. Cognitive rehabilitation following traumatic brain injury. Dement Neuropsychol. 2011;5:17-25.

146. Wicklund MR, Mokri B, Drubach DA, Boeve BF, Parisi JE, Josephs KA. Frontotemporal brain sagging syndrome: an SIHlike presentation mimicking FTD. Neurology. 2011;76:1377-82.

147. Ozyigit A, Michaelides C, Natsiopoulos K. Spontaneous intracranial hypotension presenting with frontotemporal dementia: a case report. Front Neurol. 2018;9:673.

148. Walker L, DeMeulemeester C. Spontaneous intracranial hypotension masquerading as frontotemporal dementia. Clin Neuropsychol. 2008;22:1035-53.

149. Hong M, Shah G V, Adams KM, Turner RS, Foster NL. Spontaneous intracranial hypotension causing reversible frontotemporal dementia. Neurology. 2002;58:1285-7.

150. Gharehbagh SS, Rasmussen BK, Smilkov E, Jensen RH. Spontaneous intracranial hypotension presenting with progressive cognitive decline. BMJ Case Reports CP. BMJ Specialist Journals. 2021;14:e241285.

151. Grech O, Clouter A, Mitchell JL, Alimajstorovic Z, Ottridge RS, Yiangou A, et al. Cognitive performance in idiopathic intracranial hypertension and relevance of intracranial pressure. Brain Communications. 2021;3. This article provides a good overview of the current knowledge on cognitive dysfunction and its treatment in IIH.

152. Sørensen PS, Thomsen AM, Gjerris F. Persistent disturbances of cognitive functions in patients with pseudotumor cerebri. Acta Neurol Scand. 1986;73:264-8.

153. Elbanhawy IA, Ramzy GM, Ashour AS, Khedr DM. Cognitive assessment of idiopathic intracranial hypertension patients. Egypt J Neurol Psychiatr Neurosurg. 2019;55:33.

154. Elbanhawy IA, Ramzy GM, Basheer MA, Khedr DM. Neurophysiologic tests screening cognitive impairment in idiopathic intracranial hypertension patients. Egypt J Neurol Psychiatr Neurosurg. 2018;54:7.

155. Yri HM, Fagerlund B, Forchhammer HB, Jensen RH. Cognitive function in idiopathic intracranial hypertension: a prospective case-control study. BMJ Open. 2014;4:e004376.

156. Sinclair AJ, Walker EA, Burdon MA, van Beek AP, Kema IP, Hughes BA, et al. Cerebrospinal fluid corticosteroid levels and cortisol metabolism in patients with idiopathic intracranial hypertension: a link between $11 \beta-H S D 1$ and intracranial pressure regulation? J Clin Endocrinol Metab. 2010;95:5348-56.

157. Kaplan CP, Miner ME, McGregor JM. Subject review with case study: pseudotumour cerebri risk for cognitive impairment. Brain Injury Taylor \& Francis. 1997;11:293-303.

158. Seng EK, Klepper JE. Development of the cogniphobia scale for headache disorders (CS-HD): a pilot study. Psychol Assess. 2017;29:1296-301.

Publisher's Note Springer Nature remains neutral with regard to jurisdictional claims in published maps and institutional affiliations. 